\title{
COVID-19 y su impacto en la odontología
}

\author{
COVID-19 and its impact on dentistry
}

\author{
Yamilette Tatiana Curay Camacho ${ }^{1, a}$, Valery Koo Benavides, ${ }^{1, a}$, Kassandra Guadalupe Cubas \\ Rivadeneira ${ }^{1, a}$, Katherine Rocio Huanca Cárdenas ${ }^{1, a}$, Walter Gabriel López Ramírez ${ }^{1, a}$, \\ Edar Willian Barturen Heredia ${ }^{1, a}$, José David Damián Guevara ${ }^{1, a}$, Marysela Irene Ladera Castañeda ${ }^{1, b}$
}

\section{RESUMEN}

El COVID-19 es una nueva enfermedad, este virus ha demostrado en diversos estudios tener un tiempo de incubación aproximado de cinco días. Las áreas sanitarias, incluyendo el área odontológica, se han visto en un panorama de alta vulnerabilidad y exposición, ello ha permitido modificar el rol del cirujano dentista durante esta pandemia, adoptando nuevos lineamientos de bioseguridad para preservar la salud del personal asistencial y pacientes. Es así que los protocolos en el uso de EPP, antisepsia de la cavidad bucal y desinfección se han convertido en pilares de la atención de tratamientos de urgencia y emergencia. El objetivo de la presente revisión de literatura es evidenciar la información recolectada durante la crisis sanitaria y la actualización de protocolos adoptados por los cirujanos dentistas y personal asistencial para dar una atención adecuada durante la pandemia.

PALABRAS CLAVE: coronavirus, COVID-19, odontología.

\begin{abstract}
COVID-19 is a recent disease, this virus has shown in various studies to have an approximate incubation time of five days. The health areas, including the area of dentistry, have been seen in a panorama of high vulnerability and exposure, this has allowed modifying the role of the dental surgeon during this pandemic, adopting new biosafety guidelines to keep the health of healthcare personnel and patients. Thus, the protocols for the use of PPE, oral cavity antisepsis and disinfection have become pillars of emergency and emergency treatment care. The objective of this literature review is to highlight the information collected during the health crisis and the updating of protocols adopted by dental surgeons and healthcare personnel to provide adequate care during the pandemic.
\end{abstract}

KEYWORDS: Coronavirus, COVID-19, odontology.

Doctora en Odontología, Docente. 


\section{INTRODUCCIÓN}

COVID-19 son las siglas de Coronavirus Disease 2019 (Enfermedad por Coronavirus), denominación brindada por la Organización Mundial de la Salud (OMS). Es una nueva enfermedad causada por un miembro de la familia Coronaviridae. $(1,2,3,4) \mathrm{Se}$ originó en Wuhan, Hubei, China en diciembre de 2019, y fue denominado nCOV-2019 para luego ser Coronavirus 2 del síndrome respiratorio agudo severo (SARSCoV-2) de manera oficial $(2,3)$, este virus especifico pertenece a la familia beta y su distribución en la naturaleza es amplia (2).

$\mathrm{Su}$ mecanismo de acción inicia a medida que el SARS-CoV-2 entra a la célula utilizando como receptor a la enzima convertidora de angiotensina 2 (ACE2), la misma que se encuentra en altas proporciones en el riñón, los pulmones y el corazón y a su vez tiene un papel relevante en la conversión de la angiotensina I a angiotensina 1-9, y de la angiotensina II a angiotensina 1-7. (1,3). Se ha reportado que los casos críticos de COVID-19 muestran niveles de angiotensina II elevados, y que estos se relacionan con la carga viral y el daño pulmonar(3).

La carga viral logra su punto más alto en los primeros siete días del inicio de la enfermedad, para luego comenzar a reducir de forma importante alrededor del día 10; y finalmente descender a niveles no identificables alrededor del día $21(2,3)$.

El tiempo de incubación del virus es de cinco días, reportando variaciones que oscilan entre dos y catorce días; no obstante, algunos reportes indican un tiempo de 24 días (4), y siendo más contagioso durante los primeros tres días de la aparición de los síntomas (2). El 14 de diciembre de 2020, las autoridades del Reino Unido advirtieron a la Organización Mundial de la Salud (OMS) que se tenía registrada una nueva cepa variante del SARS-CoV-2 a través de la secuenciación genómica viral, a la que se había designado como SARS-CoV-2 VUI 202012/01 (variante en investigación, año 2020, mes 12, variante 01) (5). Los estudios iniciales indicaron que la variante puede propagarse más rápidamente entre la gente. Se están llevando a cabo pesquisas para conocer si esta variante guardaría relación con alguna modificación en la severidad de los síntomas, la respuesta de los anticuerpos o la eficacia de la vacuna $(1,2,5)$.
Las ciencias de la salud a nivel mundial han experimentado una notable evolución y la odontología no ha sido ajena a ello, tanto en lo que se refiere a su área de actividad como en el reciente impacto de la pandemia COVID-19, lo que ha impuesto la necesidad de nuevos protocolos de bioseguridad para la salud de todos los involucrados en la dinámica de la atención. Actualmente se han registrado más de 2,4 millones de muertes (Organización Mundial de la Salud [OMS], 2021) y con ello, los cirujanos dentistas deben vigilar los aspectos de riesgo en la práctica odontológica teniendo en cuenta la posibilidad de infecciones en procedimientos urgentes y de emergencia, que fueron los primeros procesos en ser reactivados con los protocolos necesarios (5).

Asi mismo, se evidenció a la bioseguridad como un pilar importante para hacer frente a la pandemia, ya que esta se caracteriza como el conjunto de acciones encaminadas a la prevención, reducción o eliminación de los factores de riesgo. Basándose en esto, es deber del odontólogo, así como de las personas en general, imitar las sugerencias de los organismos de vigilancia de la salud, para que se puedan mitigar las consecuencias de la pandemia COVID-19 (6).

Este artículo de revisión tiene como objetivo brindar recomendaciones actualizadas acerca de los cuidados y medidas preventivas para hacer frente a esta nueva enfermedad, especialmente dentro del ámbito odontológico. Así mismo, busca reconocer el cuadro clínico, transmisión, diagnóstico, tratamiento e impacto de la pandemia dentro del escenario actual por la crisis sanitaria del COVID-19.

\section{COVID-19 y su impacto en la odontología}

\section{Cuadro clínico, diagnóstico y tratamiento}

\section{Signos y Sintomas}

El cuadro clínico en pacientes con COVID-19 es variable, estos pueden ser asintomáticos o presentar neumonías severas para las cuales se precise de ventilación mecánica por compromiso sistémico. Se han reportado entre los síntomas y signos más frecuentes de esta enfermedad: fiebre (98\%), tos (76 $\%$ ), linfopenia (63\%), disnea (55\%), mialgia o fatiga (44\%) (7); y en casos más graves: disnea (55\%), taquipnea e hipoxia (2). 


\section{Diagnóstico del COVID-19}

\section{Examen clínico}

El diagnóstico de la enfermedad se determina en base al examen clínico, considerando los síntomas y signos presentes en el paciente. Los exámenes de laboratorio posibilitan la confirmación o el descarte de los casos de COVID-19, teniendo como apoyo a los exámenes imagenológicos (2).

\section{Pruebas moleculares en el diagnóstico de COVID-19}

La prueba molecular que se está utilizando en todos los países para la detección de la infección con el SARS-CoV-2 es la prueba de RT-PCR sobre los genes expresados por este virus, a partir de muestras de esputo, hisopado del trato respiratorio y un lavado broncoalveolar. Se realiza el secuenciamiento del fragmento génico ORF1ab y de un fragmento de la proteína de la nucleocápside (NP). Para un diagnostico positivo, se considera como pacientes SARS-CoV confirmados a los que evidenciaron los dos fragmentos génicos (7).

\section{Exámenes imagenológicos}

El empleo de exámenes auxiliares como la tomografía computarizada puede presentar algunos hallazgos incluso antes y durante el cuadro clínico; evidenciándose una infiltración bibasal en los pulmones (2).

\section{Tratamiento del COVID-19}

En la actualidad, gracias a los grandes avances científicos, se cuenta con vacunas de alta efectividad (65 a 95\%), las cuales están siendo adquiridas por los gobiernos de todo el mundo $(2,7)$.

Y pese a que se están desarrollando favorablemente los procesos de vacunación, el tratamiento actual es básicamente sintomático. Se han estado administrando algunos fármacos tales como la hidrocloroquina, Liponavir y Remdesivir, sin embargo, no gozan de una entera eficiencia, ya que estos fármacos generan efectos adversos considerables (5).

\section{Rutas potenciales de transmisión}

El modo de transmisión de esta enfermedad infecciosa aún es materia de investigación continua; (2) Sin embargo, por lo poco que se conoce este virus se propaga por medio de gotas (gotitas de Flügge) producidas al toser, estornudar o hablar; vía feco-oral y contacto directo (entre personas) o indirecto (por superficies contaminadas) (1). Teniendo en cuenta el modo de transmisión, todo aquel que esté involucrado en tratamientos odontológicos se hallan entre las personas con un alto riesgo de infectarse (8).

\section{Propagación del COVID-19 en el ámbito odontológico}

Como se evidencia en la literatura, el paso directo y la propagación del nuevo coronavirus a través de gotitas respiratorias es muy común(1). Además, por la naturaleza del periodo de incubación en algunos casos no muestra signos clínicos (4). Por lo tanto, tanto los pacientes como los profesionales dentales corren un riesgo bilateral de estar expuestos a patógenos virales que pueden transmitirse a través de la cavidad bucal y el tracto respiratorio durante las visitas al dentista (8). Los procedimientos dentales, por su naturaleza, tienen un alto riesgo de infección por COVID-19 debido a la comunicación frente a frente, muy de cerca, con el equipo asistencial y el paciente. Además, la contaminación frecuente con saliva, sangre y otros fluidos corporales, así como el uso de instrumentos rotativos afiliados y de alta velocidad, aumenta el riesgo de infección y transmisión en las consultas dentales (1).

\section{Medidas preventivas en la práctica odontológica Equipos de Protección Personal (EPP)}

Es extremadamente relevante implementar unas medidas preventivas en la práctica odontológica como es el implemente de los equipos de protección personal (EPP) en los centros de atención odontológica, que incluya a personal asistencial y administrativo; de forma que se garantice la protección tanto de los pacientes como de los profesionales, para seguir correctamente un protocolo que permita evitar contagios o propagaciones dentro de la práctica odontológica. Se sugiere el uso de una lista de verificación, la cual debe contener elementos obligatorios, tales como: batas impermeables 
descartables de largo completo (EPP intermedio), mamelucos (EPP Avanzado), respiradores N95, FFP2 o FFP3, careta completa o visera, guantes (9), y protectores oculares (10).

\section{Lavado e higienización las manos}

El lavado o higiene de manos (la disposición más importante para aminorar el peligro de transmisión del virus) con jabón y agua, o con una sustancia a base de alcohol, principalmente luego de entrar en contacto con sus secreciones; es una de las medidas más destacadas por la OMS y las autoridades sanitarias para limitar la propagación del coronavirus. (11) El refuerzo de una buena higiene de manos y el seguimiento del protocolo es vital, y la falta de estos puede crear desafíos innecesarios para el control del contagio durante una pandemia. Se ha sugerido que los cirujanos dentistas tiene que lavarse las manos antes de revisar a un paciente, previo a cualquier procedimiento dental, luego de atender al paciente y después de pulsar cualquier equipo y superficies circundantes sin desinfectar, tras contacto con la mucosa oral, heridas o piel dañada, sangre, fluidos corporales, saliva y excretas $(12,13)$.

El uso de desinfectantes para manos a base de alcohol con mínimo $60 \%$ de etanol o isopropanol también se ha documentado como una simple técnica de control de infecciones que puede inactivar virus envueltos, incluidos los coronavirus (14).

\section{Uso de enjuague bucal antes de la atención odontológica}

El virus SARS-CoV-2 puede permanecer en las superficies por horas, e incluso días. Es por ello que antes del examen intraoral, se recomienda el uso de un colutorio que contenga peróxido de hidrógeno al $1 \%$ o Povidona yodada al $0,2 \%$, debido a que el síndrome respiratorio agudo severo-coronavirus- 2 es muy susceptible a la oxidación (15), ello ayuda a la ya mencionada reducción de la carga viral en las gotitas $\mathrm{y}$ aerosoles $(11,14,15)$.

\section{Uso de diques de goma para el aislamiento}

Una de las formas más simples y prácticas de reducir la contaminación de la cavidad bucal y lograr el control efectivo de la humedad es la aplicación de un dique de goma. $(10,15)$ Se ha demostrado que minimiza la producción de saliva y aerosoles contaminados con sangre, especialmente durante los procedimientos realizados con el uso de la turbina de las piezas de mano de alta velocidad e instrumentos ultrasónicos $(6,8,15)$. La literatura indica que el uso de diques de caucho resultó en una disminución del $70 \%$ de partículas suspendidas en el aire dentro de aproximadamente tres pies de diámetro del campo operativo. $(8,10,14,15)$ Con respecto a la toma de radiografías, se sugiere el empleo de técnicas extraorales tales como la radiografía panorámica o la tomografía computarizada Cone Beam, debido a que las técnicas intraorales suelen generar secreción salival o tos. De ser posible, se sugiere utilizar en estos casos también diques de goma o en su defecto realizar el procedimiento acompañado por un suctor de saliva y un trabajo a cuatro manos (15).

\section{Impacto inmediato del COVID-19 en la práctica odontológica}

Luego de que la OMS declarara la pandemia sanitaria el 11 de marzo del $2020(1,2,8,16)$, diversos autores publicaron estudios que consideraban a la odontología como una de las profesiones con mayor riesgo de infección ante el COVID-19, ocupando incluso en muchos de ellos el primer lugar (17).

La Asociación Dental Americana (ADA) anunció que se debería limitar a la atención dental solo los casos de emergencia (Dolor severo e incontrolado; Infección diseminada, recurrente o continua; Diente permanentemente avulsionado; y trauma severo). De igual forma, se hace obligatorio el uso de los equipos de protección personal (EPP) apropiado para minimizar el riesgo de transmisión durante los tratamientos dentales de emergencia, medidas preventivas como exhibición de carteles de comunicación sobre COVID-19, adopción de mecanismos para establecer pacientes potenciales con síntomas antes de las visitas al dentista, la interrupción del tratamiento dental para las personas con COVID-19 y reducción de controles de rutina $(12,16)$.

\section{Rol del odontólogo frente al COVID-19}

La pandemia COVID-19 ha cambiado la forma en la cual se han organizado los equipos de salud. En primer lugar, el número de contagios a nivel mundial, 
ha provocado un desabastecimiento de insumos, medicamentos y personal médico, llevando al fracaso a los sistemas de salud. Por otro lado, los odontólogos han sido llamados solo a posponer tratamientos sin carácter de urgencia, sin incluirlos dentro del personal asistencial para el control de la enfermedad (17). Sin embargo, estos como personal de salud deberían entrar en la necesidad de ser capacitados y redistribuidos, para compartir sus habilidades y competencias con el fin de formar parte del equipo asistencial $(16,17)$.

En estas circunstancias, el odontólogo siempre debe custodiar la salud del paciente y su personal de trabajo por lo que es indispensable el empleo de los equipos de protección personal (EPP), respeto a los protocolos de atención, bioseguridad y la responsabilidad que tiene con el paciente para con su equipo. Una razón adicional para que el odontólogo forme parte del equipo de salud ante la pandemia es que la boca es un medio altamente contaminante (12). En el estudio de Castro y Valenzuela se evidenció que gran parte de los odontólogos peruanos encuestados siente que el rol que cumplen en este momento involucra mayor complejidad y cuidado durante la atención de pacientes (11); asimismo, ellos implementarían sus medidas de prevención de acuerdo lineamientos protocolizados por entidades sanitarias como como la Organización Mundial de la Salud (OMS), Organización Panamericana de Salud (OPS), Colegio Odontológico del Perú (COP) y Ministerio de Salud (MINSA) $(11,12)$.

\section{Protocolos para detección de pacientes de riesgo}

Los profesionales dentales deben detectar e identificar a los pacientes con COVID-19 para contrarrestar la propagación de la enfermedad infecciosa $(6,8)$. No se debe realizar ningún tratamiento dental de rutina a pacientes con sintomatología o en la etapa inicial de la infección, y se debe alentar a estos pacientes a que se pongan en cuarentena y se auto aíslen $(6,7$. La primera medida de detección sería tomar la temperatura corporal de cada paciente con un termómetro infrarrojo sin contacto, luego completar un cuestionario respondiendo preguntas para determinar si han presentado sintomatología clínica de COVID-19 como fiebre, tos persistente o compromiso respiratorio en las últimas dos semanas. Se debe también registrar cualquier contacto con personas que dieron positivo en la prueba de COVID-19 o con síntomas de alerta (15). Si los resultados de este protocolo indicaran potencial infección de COVID-19, se le debe recomendar al paciente aislamiento en su casa y que se comunique con su centro de atención de COVID-19 si los síntomas empeoran (3).

\section{Protocolos de atención en Odontología}

Previo a la ejecución de cualquier tratamiento dental, bien sea urgencia o emergencia, el cirujano dentista deberá estar informado sobre el curso de la pandemia en su ciudad, de esta manera podrá ofrecer una atención segura. Adicionalmente, se sugiere tomar una capacitación al personal de apoyo, donde se fomente la importancia de los cuidados y autocuidados, unificando concepciones para acrecentar las medidas preventivas durante una atención odontológica y asimismo paliar la propagación de este nuevo virus (17).

El profesional debe emplear el equipo de protección personal (EPP), imitando los patrones recomendados para su uso y retiro de forma adecuada. Una vez que el paciente ya esté en el sillón odontológico, se iniciara con la antisepsia de la cavidad bucal mediante las soluciones indicadas $(4,15)$.

Antes de comenzar cualquier tratamiento odontológico el paciente tiene que firmar su consentimiento informado, en el cual además debe incorporar su aceptación ante el posible riesgo de contaminación cruzada a la que está siendo expuesto. Algunos tópicos deben ser informados por el paciente de forma clara como los que guardan relación a su contacto previo con personas infectadas por el COVID-19 o con síntomas como: fiebre, disnea, fatiga, tos, disnea, anosmia entre otras. El odontólogo deberá ir modificando las interrogantes sobre la sintomatología de alerta ya que cada día nos encontramos con nuevas manifestaciones $(6,12)$.

Así también se debe tomar una gran importancia al valorar el compromiso de la dolencia odontología y tomar una decisión apropiada y cuidadosa. Por ello, cada paciente se considera potencialmente contagiado por el virus, por lo que se debe cumplir con normas de desinfección y control de infecciones, sin esto, 
es recomendable eludir cualquier tipo de atención o referirlo a un lugar especializado que cumpla con todas las medidas de bioseguridad $(7,11)$.

\section{Protocolos de desinfección del ambiente clínico}

En un entorno sanitario o en un no sanitario, la desinfección siempre tiene que estar presente. Se debe desinfectar todas las superficies que estén en contacto con mayor frecuencia con cloro o alcohol $(11,18)$.

Algunas consideraciones preventivas adicionales en el campo odontológico son el uso de filtros de partículas de alto rendimiento (HEPA), limpieza y desinfección de superficies. La limpieza debe progresar desde las áreas menos sucias a las más sucias, y desde los pisos más elevados hasta los inferiores para que los escombros caigan al piso y se limpien al final $(17,18)$.

En caso del cloro como sustancia de limpieza y desinfección, se puede usar en formas líquidas (Hipoclorito de sodio), sólidas o en polvo (Hipoclorito de calcio), siguiendo las instrucciones del fabricante. En caso del cloro en forma líquida se utilizaría [\% de cloro en hipoclorito de sodio líquido / \% de cloro deseado] - 1 = Total de partes de agua por cada parte de hipoclorito de sodio; y en caso del cloro en forma sólida o en polvo usaríamos $[\%$ de cloro deseado \pm $\%$ de cloro en polvo o gránulos de hipoclorito] $\times 1$ $000=$ gramos de polvo de hipoclorito de calcio por cada litro de agua. (18) Las soluciones de cloro se tienen que almacenar en envases opacos, en un área cubierta y bien aireada para evitar la exposición a la luz solar directa, ya que puede decaer rápidamente $(6,8,17,18)$.

Es fundamental que los equipos médicos y dentales sigan un protocolo de desinfección efectivo y estricto tanto para áreas clínicas como comunitarias. En general, todas las superficies deben limpiarse y desinfectarse al más alto nivel de acuerdo con las pautas y requisitos locales. Las zonas comunes y las instalaciones públicas deberán limpiarse y desinfectarse de forma periódica, lo que incluirá la desinfección total de todas las manijas de las puertas, sillas, escritorios, pantallas táctiles y monitores. Si hay un ascensor en el edificio debería desinfectarse con frecuencia y se debe alentar a todos a usar mascarillas y evitar el contacto directo con los botones del ascensor $(11,12,16,17)$.

\section{Gestión de Residuos clínicos}

Los desechos clínicos deben acopiarse en un área de almacenamiento temporal segura, y todos los instrumentos y artículos reutilizables deben tratarse previamente: limpiarse, desinfectarse, esterilizarse y almacenarse adecuadamente de acuerdo con los protocolos. Los desechos clínicos generados después del tratamiento de pacientes con COVID-19 positivos deben considerarse desechos clínicos infecciosos y almacenarse en bolsas de desechos clínicos dentro de un área designada. La superficie de las bolsas del paquete debe marcarse y eliminarse de acuerdo con las reglamentaciones locales y los requisitos para la gestión de desechos médicos $(11,16)$.

\section{Teleodontología}

La teleodontología ha mostrado una eficaz forma de acceso, siendo un medio de equidad e inclusión, con ventajas relacionadas al aumento de capacidad resolutiva, una reducción del tiempo de espera y costos de los tratamientos. La teleodontología puede ser eficiente en los triajes de lesiones orales en las áreas rurales y en los pacientes que tengan limitado acceso a los recursos sanitarios $(6,16)$.

El empleo de las tecnologías de información y comunicación (TIC) sucede como parte de las funciones de la salud pública odontológica en países de América Latina, para mejorar la educación continuada y búsqueda colaborativa entre instituciones nacionales y extranjeras. Ante la crisis por COVID-19, emergió una necesidad de incorporar la teleodontología en la rutina de la atención odontológica. La pandemia introdujo preocupaciones extras a los profesionales y beneficiarios de los servicios de salud oral, entre ellos los pacientes inmunosuprimidos o con enfermedades que comprometían un mayor riesgo en la consulta presencial (11).

En general, bajo el contexto de la pandemia se recomienda el uso de la teleodontología bajo un protocolo bien establecido por cada país, ello incluye un triaje, consultas y evaluación de signos (12). 


\section{Impacto del COVID-19 en la investigación odontológica}

Al igual que en todo el mundo el COVID-19 ha llevado a una crisis en la educación general y con mayor énfasis en la educación superior universitaria con un impacto superior al $87 \%$. Ante el incremento de semanas al estado de emergencia, se autorizó el comienzo de actividades en las universidades vía online, incitando a los estudiantes a tomar énfasis en proyectos y estudios de investigación dirigidos al COVID-19 $(6,19,20)$.

Muchos estudiantes se vieron afectados por el brote de COVID-19 debido a la necesidad de detener los procedimientos dentales no urgentes y las actividades de extensión. Además, la mayoría de los proyectos de investigación dental de laboratorio fueron suspendidos debido a las políticas gubernamentales e institucionales obligatorias que limitan las actividades no esenciales. Por lo tanto, algunos investigadores dentales cambiaron su enfoque hacia otro campo o medio de investigación en línea, como la realización de encuestas virtuales y la realización de revisiones de literatura (18).

Las áreas potenciales para futuras investigaciones odontológicas relevantes para el brote de COVID-19 pueden incluir: problemas de salud pública dental, impacto de la pandemia en la odontología y el sector odontológico, control de infecciones cruzadas, papel de los profesionales dentales, innovaciones en la consulta remota e investigación en biología oral $(11,19)$.

\section{Impacto a largo tiempo del COVID-19 en la Odontología}

Según algunos autores no se sabe a precisión cual será el impacto a largo plazo del COVID-19 en la odontología, pero se tiene en claro que la reinvención del proceso educativo es quizás uno de los retos más grandes. Un rasgo importante es la nueva educación asistida que se ha ido modificando, así como la necesidad de nuevas maneras de ver la atención clínica, eje transversal (20).

Las observaciones de los autores y la evaluación de la situación actual sugieren que los costos de proporcionar tratamiento dental pueden aumentar en el futuro debido al uso extra de EPP, y mayores tiempos de espera debido a la necesidad de segregación de pacientes en las salas de espera, lo que reduce la cantidad de pacientes atendidos diariamente. Además, se supone que puede haber un aumento en la demanda de consultas electrónicas $(1,2,11)$. En consecuencia, la demanda de tratamientos dentales electivos podría disminuir y los pacientes podrían elegir extracciones de emergencia en lugar de tratamientos conservadores como el tratamiento de conducto o en caso contrario, prestar más atención a su salud bucal y dental mejorando su higiene bucal $(12,19)$.

El efecto del COVID-19 es devastador para el sector privado. Algunas agencias de calificación crediticia cambiaron la calificación de las compañías dentales a negativa en abril de 2020, esperando una enorme reducción en el volumen de pacientes para el año financiero 2021. Si estas especulaciones se materializan en el futuro, la mayoría de las prácticas dentales experimentarán una reducción del $66 \%$ en sus ganancias o no podrán obtener ninguna ganancia (20).

\section{DISCUSIÓN}

La odontología viene pasando por intensas transformaciones en los últimos años, tanto en la formación académica como la práctica odontológica. En un estudio publicado en el 2020 por Díaz y Toro, se indicó que, pese a que no hay datos específicos por parte de la OMS, es evidenciable que el virus SARS$\mathrm{CoV}-2$ puede permanecer en las superficies por horas e incluso hasta días, por lo que es necesaria una mayor protección en la práctica odontológica para evitar la contaminación indirecta (3).

Santos-Velázquez, Panizo, Diaz, y Sanchez indicaron que el virus puede ser inactivado con rayos ultravioletas o calor (9); sin embargo, SabinoSilva, Jardim y Siqueira indicaron que el virus aún está en estudio y que su comportamiento no está bien definido, por lo que es imposible asegurar que medidas como el uso de desinfectantes, rayos ultravioletas o inactivación por calor no pueden ser afirmadas, se recomendó entonces, recurrir al uso de materiales desechables y recubrimiento de superficies (15). 
Quincho-Rosales, Castro-Rodríguez y GradosPomarino muestran varios aspectos importantes referentes a la repercusión de la pandemia por COVID-19 en la odontología, por lo que se han implementado ciertas medidas o protocolos de emergencia (11). Cabe mencionar que no siempre estaremos en emergencia por dicha pandemia, es por ello que es necesario abordar temas sobre protocolos de bioseguridad en odontología mediante documentos técnicos y que estos formen parte de la realidad nacional.

\section{CONCLUSIÓN}

En conclusión, la aparición la pandemia por la COVID-19 ha puesto a la atención odontológica en un escenario difícilmente imaginado por lo que es de suma urgencia que el odontólogo tenga conocimiento de las características de este virus, vías de transmisión, sintomatología y todo lo que permitan identificar a los pacientes infectados y tomar las medidas estratégicas para evitar la propagación. De igual forma, la atención odontológica se ha visto obligada a adoptar nuevos protocolos como: utilización de implementos de protección personal, lavado e higienización de manos, cantidad-frecuencia de pacientes y desinfección de superficies. También ha sido oportuno modificar las modalidades de atención al paciente en la consulta (teleodontología) y ser más estrictos en el manejo de los desechos del consultorio. Por ende, nos damos cuenta que la llegada de esta pandemia de COVID-19 ha tenido un claro impacto en la atención odontológica sin embargo no existe literatura que asegure que estas nuevas medidas adoptadas por la pandemia prevalezcan a futuro.

Conflicto de intereses: los autores no tienen conflicto de interés con este informe.

Aprobación de ética: No se requiere

Financiamiento: Ninguno.

Contribuciones de los autores: Todos los autores contribuyeron a este manuscrito.

\section{Correspondencia:}

Yamilette Curay Camacho

Av. Del Pacífico 180 Torre E2 dpto.102, San Miguel, Lima, Perú

Celular de contacto: +51991062373

Correo electrónico: yamicurcam@hotmail.com

\section{REFERENCIAS BIBLIOGRÁFICAS}

1. Ikhlaq A, Bint-e-Riaz H, Bashir I, Ijaz F. Awareness and attitude of undergraduate medical students towards 2019 coronavirus. Pak J Med Sci. 2020; 36: :S32-S36. doi: 10.12669/pjms.36.COVID19-S4.2636.

2. Farhana, KM, Mannan, KA. Knowledge and perception towards Novel Coronavirus (COVID 19) in Bangladesh. International Research Journal of Business and Social Science. 2020; 6(2):76-87.

3. Díaz F, Toro A. SARS-CoV-2/COVID-19: el virus, la enfermedad y la pandemia. Med Lab. 2020; 24(3): 183205.

4. Chandra J. Knowledge, attitude, and behavior of covid-19 among dental students at north india dental college- a questionnaire survey. Revista europea de ciencias biomédicas y farmacéuticas. 2020; 7(1): 258264.

5. Organización Mundial de la Salud. Therapeutics and COVID-19: Living guideline. Canadá: Organización Mundial de la Salud; 2020.

6. Tuñas ITC. Doençapelo Coronavírus 2019(COVID-19): Uma abordagem preventiva para Odontologia. Revista Brasileira de Odontologia. 2020; 77:1-6

7. Aguilar-Ramírez P, Enriquez-Valencia Y, QuirozCarillo C, Valencia-Ayala E, de Léon- Delgado J, Pareja-Cruz A. Pruebas diagnósticas para la COVID-19: la importancia del antes y el después. Horiz Med (Lima). 2020; 20(2): e1231. (Citado el 15 de enero del 2021)Disponible en: http://www.scielo. org.pe/pdf/hm/v20n2/1727-558X-hm-20-02-e1231.pdf

8. Peng X. Transmission routes of 2019-nCoV and controls in dental practice. International journal of oral science. 2020 ; 12 (9): 1-6. doi: 10.1038/s41368-0200075-9

9. Santos-Velázquez T, Panizo S, Díaz Y, Sánchez N. Conocimientos de estomatólogos sobre prevención y control de la COVID-19. Revista Electrónica Dr. Zoilo E. Marinello Vidaurreta; 45(3):0-0. (Citado el 15 de enero del 2021)Disponible en: http://revzoilomarinello. sld.cu/index.php/zmv/article/view/2292

10. Christiani J. Covid-19: una mirada hacia la seguridad del paciente en odontología. Rev. Asoc. Odontol Argent. 2020; 108 (1): 88-94.

11. Quincho-Rosales D, Castro-Rodríguez Y, GradosPomarino S. Consideraciones sobre la atención estomatológica en el Perú durante la pandemia por la COVID-19. Rev Cubana Estomatol. 2020; 57(3): e3315. (Citado el 15 de enero del 2021)Disponible en: http://www.revestomatologia.sld.cu/index.php/est/ article/view/3315

12. Lai J, Ma S, Wang Y, etal. Factors Associated with Mental Health Outcomes Among Health Care Workers Exposed to Coronavirus Disease 2019. JAMA Netw Open. 2020; 3(3):e203976. doi: 10.1001/ 
jamanetworkopen.2020.3976

13. Córdova-Aguilar A, Germán Rossani A. COVID-19: Revisión de la literatura y su impacto en la realidad sanitaria peruana. Rdo Fac Medicina Tararear J. 2020; 20 (3): 471-477.

14. Ge Z, Yang L, Xia J, Fu X, Zhang Y.Possible aerosol transmission of COVID-19 and special precautions in dentistry. J Zhejiang Univ Sci B. 2020;21(5):361-368. doi: 10.1631/jzus.B2010010

15. Sabino-Silva R, Jardim A, Siqueira W. Coronavirus COVID19 impacts to dentistry and potential salivary diagnosis. Clin Oral Investig. 2020; 24(4):1619-1621.

16. Al-Amad S, Awad M, Edher F. The effect of rubber dam on atmospheric bacterial aerosols during restorative dentistry. J Infect Public Health. 2017;10(2):195-200.

17. Santos-López M, Catrian-Fernández H. COVID-19 y el nuevo rol del odontólogo en el equipo de salud. Int. J. Odontostomat. 2020; 14(3): 296-298.
18. Organización Mundial de la Salud. Clearing and desinfection of environmental surfaces in the context ofCOVID-19: Interim guidance. Ginebra: Organización Mundial de la Salud; 2020. (Citado el 15 de enero del 2021)Disponible en: https://www.who.int/publications/ $\mathrm{i} /$ item/cleaning-and-disinfection-of-environmentalsurfaces-inthe-context-of-covid-19

19. Velázquez L, Valenzuela C, Murillo F. Pandemia COVID-19: repercusiones en la educación universitaria. Odontol Sanmarquina. 2020; 23(2): 203-205.

20. Gutiérrez B, Perdomo A. El reto del ejercicio odontológico en el marco de la pandemia y futuro post COVID-19: una reflexión desde la salud pública. Salutem Scientia Spiritus. 2020; 6(1): 55-62.

Recibido : 24-02-2021

Aceptado : 06-04-2021 